\title{
How FinTech Enters China's Credit Market
}

\author{
By Harald Hau, Yi Huang, Hongzhe Shan, and Zixia Sheng*
}

Online trading platforms generate abundant vendor and consumer data accessible for credit analysis. Big data can thus give birth to FinTech firms that use both cheaper (online) distribution channels and better credit analysis to compete with traditional bank credit. China has been at the forefront of these developments due to the pervasive use of online trading platforms and an underdeveloped banking system which excludes large segments of the rural and bank remote population from traditional bank credit. This article documents stylized facts about the entry of FinTech credit into China's credit market for small firm (vendor) credit.

Access to a better credit technology should benefit particularly those borrowers who represent a larger (ex ante) credit risk and are often excluded from traditional bank credit. More borrower information allows lenders to price risk more accurately and to tailor credit terms to the risk characteristics of specific groups. The real-time sales monitoring of trading platforms endow FinTech companies with a potentially significant information advantage over traditional banks to undertake improved screening.

\footnotetext{
*Hau: University of Geneva, 42 Bd du Pont d'Arve, 1211 Geneva, Switzerland, CEPR, and Swiss Finance Institute (email: prof@haraldhau.com); Huang: Graduate Institute-Geneva, Maison de la paix, Chemin Eugene-Rigot 2, 1202 Geneva, Switzerland, and CEPR (email: yi.huang@ graduateinstitute.ch); Shan: University of Geneva, $42 \mathrm{Bd}$ du Pont d'Arve, 1211 Geneva, Switzerland, and Swiss Finance Institute (email: hongzhe.shan@unige.ch); Sheng: Ant Financial Group. We are grateful to workers at Ant Financial and AliResearch for their support, and Sibo Liu at Hong Kong University for generously sharing his GPS data on Chinese bank branches. This research project benefited from a research grant from the Graduate Institute and a Sinergia Research Grant from the Swiss National Science Foundation (SNSF). The authors declare that they have no relevant or material financial interests that relate to the research described in this paper. Ant Financial did not exercise any influence on the content of this paper, but requires confidentiality of the (raw) data.

${ }^{\dagger}$ Go to https://doi.org/10.1257/pandp.20191012 to visit the article page for additional materials and author disclosure statement $(\mathrm{s})$.
}

We conjecture that FinTech credit (i) expands the extensive margin of credit to borrowers of lower credit scores and (ii) faces a more intensive use of its credit lines from borrowers with lower credit scores. The evolution is reminiscent of the expansion of US household credit with the democratization of credit cards in the 1980s (Mann 2006; Livshits, Mac Gee, and Tertilt 2016).

We confront both conjectures with extensive credit data from China's largest provider of automated online credit called Ant Financial (https://www.antfin.com). This FinTech (or TechFin) company uses the transaction data from Alibaba's online trading platform Taobao (www. taobao.com) to undertake an (algorithm-based) automated credit analysis and offers a credit line to Taobao vendors with a sufficiently high credit score (Hau et al. 2018). We study a comprehensive dataset on 28.67 million monthly credit offers by Ant Financial to 2.89 million Taobao vendors and study the take-up rate and (percentage) use of FinTech credit lines across the vendor population. Detailed information on the borrower allows us to infer local credit market supply and describe how the FinTech credit offer is used as a function of borrower characteristics and conditional on local credit market conditions.

First we sketch a simple credit market model with a FinTech firm entering the market. The model yields testable predictions that are then confronted to the credit data from Ant Financial.

\section{A Model of FinTech Credit}

We assume a unit interval of potential borrowers of observable type $i \in[0,1]$ with a unit credit demand. Each potential borrower $i$ can be either a safe $(S)$ or risky $(R)$ type with probabilities $p^{S}$ and $p^{R}=1-p^{S}$, respectively. Safe borrowers only request loans up to an interest rate $\bar{r}^{S}$, whereas risky borrowers still demand loans if the interest rate is much higher, say up to a limit $\bar{r}^{R}>\bar{r}^{S}$. The default probability of 
risky borrowers decreases along the unit interval with type $i(\gamma>0)$,

$$
p^{D}= \begin{cases}e^{-\gamma i} & \text { for } i=R \\ 0 & \text { for } i=S\end{cases}
$$

whereas the safe borrower type never defaults.

A credit technology represents a signal which improves identification of the safe borrower type relative to the ex ante probability of $p^{S}$. Let $p^{S \mid+}$ denote the posterior probability of having correctly identified a safe borrower conditional on a positive signal, where $p^{S}<p^{S \mid+}<1$, and $p^{R \mid+}=1-p^{S \mid+}$ the (type one) error that the borrower is risky in spite of the positive signal from a credit analysis.

We call a (new) credit technology superior if it reduces the set of potential borrowers that are risky conditional on a positive signal, for example by an increment $\Delta>0$. We assume a negative signal makes lending unprofitable. Let the credit score of borrower type $i$ under the technology improvement $\Delta$ be denoted by one minus the probability of default; i.e., $C S_{i}^{F T}=1-e^{-\gamma i}\left(1-p^{S \mid+}-\Delta\right) . \quad$ Initially, we assume a competitive credit market where traditional creditors (banks) operate with an identical credit technology with $\Delta=0$ and identical signals. Banks face local refinancing $\operatorname{cost} r^{L}<\bar{r}^{S}$.

Competitive Benchmark without the FinTech Firm.-The competitive equilibrium is characterized by a credit yield

$$
r_{i}^{C}=r^{L}+e^{-\gamma i}\left(1-p^{S \mid+}\right)\left(1+r_{i}^{C}\right),
$$

as long as $r_{i}^{C} \leq \bar{r}^{S}$. Only borrowers on the interval $\left[i^{C}, 1\right]$ are offered credit, where we have

$$
i^{C}=-\frac{1}{\gamma} \ln \left[\frac{\bar{r}^{S}-r^{L}}{\left(1-p^{S \mid+}\right)\left(1+\bar{r}^{S}\right)}\right]>0
$$

Extending credit to low-quality borrowers with $i<i^{C}$ is not optimal as this can only be done at a rate higher than $\bar{r}^{S}$ where the safe borrower type no longer requests credit and the composition the borrowers switches to only risky borrowers.

Market Entry of a New Credit Technology.Next, we assume that the FinTech credit provider introduces a better credit technology which reduces the (type II) error of incorrect borrower screening by a probability of $\Delta$. The entrant's critical borrower quality threshold is

$$
\text { (4) } i^{F T}=-\frac{1}{\gamma} \ln \left[\frac{\bar{r}^{S}-r^{N}}{\left(1-p^{S++}-\Delta\right)\left(1+\bar{r}^{S}\right)}\right]<i^{C} \text {, }
$$

where $r^{N}$ denotes the FinTech firm's refinancing rate at the national level. For simplicity, we assume that the FinTech firm can only access a small share $\delta>0$ of (e-commerce) borrowers on the unit interval $i \in[0,1]$ (unknown to the incumbent banks), which implies that the adverse selection problem from better creditor selection for the incumbents can be neglected. ${ }^{\mathbb{T}}$ Under (Bertrand) price competition the optimal interest rate charged by the FinTech entrant follows as

$$
\text { (5) } r_{i}^{F T}=\left\{\begin{array}{ll}
\bar{r}^{S} & \text { for } i^{F T} \leq i<i^{C} \\
r_{i}^{C}-\epsilon & \text { for } i^{C} \leq i \leq 1
\end{array},\right.
$$

where $\epsilon>0$ represents a small discount on the competitive price $r_{i}^{C}$ of the incumbents to entice borrower switching. Thus, pure price competition implies that the FinTech firm captures the entire share $\delta$ of accessible borrowers on the interval $\left[i^{F T}, 1\right]$ as illustrated in Figure 1.

PROPOSITION 1 (Extensive Margin Extension): The FinTech firm serves a share $\delta$ of accessible borrowers of type $i \in\left[i^{A F}, 1\right]$; it expends the extensive margin of credit supply to borrowers of type $i \in\left[i^{A F}, i^{C}\right]$ previously not served by the incumbent banks.

Limited Creditor Substitutability.-Credit competition is unlikely to be pure price competition. Borrowers may incur heterogeneous switching cost for moving to the new credit technology. We assume that the mass of borrowers at any point $i \in[0,1]$ is uniformly spread over a second unit interval $s \in[0,1]$ and that switching costs increase linearly for borrower

\footnotetext{
${ }^{1}$ Note that this assumption is not implausible as long as FinTech credit represents only a small percentage of the overall small firm credit. In 2016, FinTech credit represented only 0.37 percent of the overall volume of small firm credit. Generally "cream skimming" of safe borrowers by the FinTech firm increases credit risk for lenders with an inferior credit technology.
} 


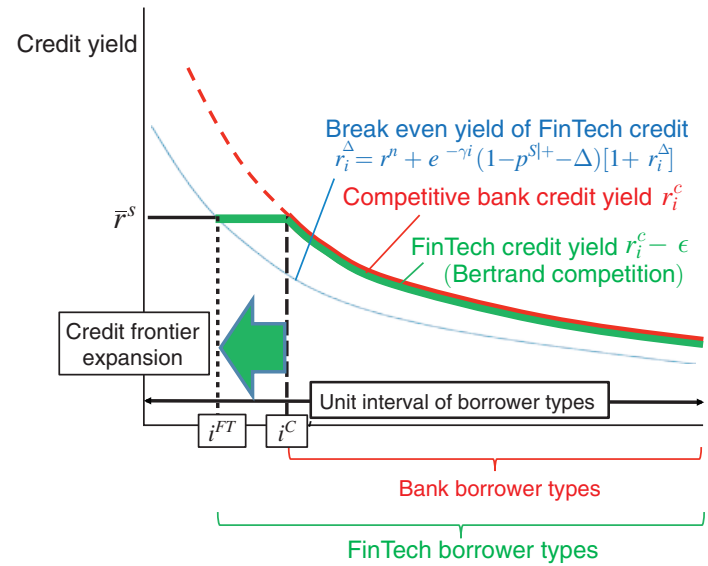

Figure 1. Credit Frontier Expansion under FinTech

$(i, s)$ by $c(i, s)=\theta s$. Borrowers not previously served by traditional banks have zero switching cost. The FinTech entrant $(F T)$ is now facing a downward sloping demand curve for a share $\delta$ of every borrower type $i \in\left[i^{C}, 1\right]$. Monopolistic pricing implies that the entrant serves a share $s_{i}$ (among all accessible creditors) with

$$
s_{i}=\left\{\begin{array}{ll}
1 & \text { for } i^{F T} \leq i<i^{C} \\
\frac{1}{2 \theta}\left(r_{i}^{C}+1-\frac{1+r^{N}}{C S_{i}^{F T}}\right) & \text { for } i^{C} \leq i \leq 1
\end{array},\right.
$$

where $C S_{i}^{F T}$ denotes the credit score of the FinTech firm given to type $i$ and $r_{i}^{C}$ the bank credit rate which depends on bank financing costs $r^{L}$.

PROPOSITION 2 (FinTech Market Share by Credit Scores): The share of borrowers using the new credit technology is strictly decreasing in the credit scores $C S_{i}^{F T}$ of borrower type $i$ conditional on local credit market conditions $r^{L}$.

\section{PROOF:}

Follows directly from $d s_{i} / d C S_{i}^{F T}<0$.

Intuitively, the FinTech firm's competitive (information) advantage is largest for low-quality borrower types, which translates into a higher market share under limited creditor substitutability. Also, the following result holds.
PROPOSITION 3 (FinTech Market Share by Local Credit Scarcity): The share of borrowers using the new credit technology is larger in local credit markets with a shortage of bank credit represented by higher bank financing costs $r^{L}$.

\section{PROOF:}

Follows directly from $d s_{i} / d r^{L}>0$.

\section{Evidence}

The key model prediction is that FinTech credit is relatively more attractive for borrowers with low credit scores who are often excluded from bank credit. For those borrowers, the FinTech entrant enjoys the largest competitive advantage in credit provision. We verify this proposition using credit account data from Ant Financial. Over the period August 2014 to September 2016, Ant Financial provided online credit offers to more than 2.89 million online vendors trading on China's largest retail site called Taobao. Ant Financial uses the transaction data on Taobao to generate credit scores for the online vendors and provides an automated online credit offer if the vendor passes a certain minimum credit score.

The credit conditions offered by Ant Financial depend on the vendor characteristics. Using a large number of vendor characteristics as control variables, we can explore variations in the regional FinTech (or online) credit demand by estimating city fixed effects for the local vendor use of FinTech credit. Generally, the FinTech credit demand is larger in cities with (i) less overall credit supply (relative to local GDP) by traditional banks; (ii) a higher share of stateowned enterprise (SOE) employment (because SOEs tend to monopolize traditional bank credit); and (iii) in rural areas with a larger distance of the vendor to local bank branches. We sort China's cities into different quintiles by the overall demand for FinTech credit conditional on all vendor characteristics. Figure 2 shows the geographic variation in FinTech credit use, which (to a large extent) captures the local scarcity of traditional bank credit throughout China. The heat map reveals the largest credit scarcity (proxied here by the use of FinTech credit) in China's southern coastal cities.

Next we document how the use of FinTech credit varies with a vendor's credit rating and local bank credit availability. Table 1 sorts all 


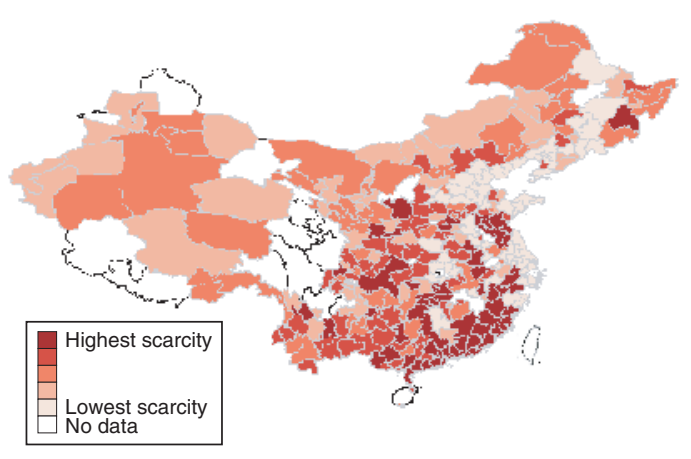

Figure 2. CRedit Scarcity by City

Taobao vendors first into groups A to E according to the availability of traditional bank credit measured by the local Loan-to-GDP ratio. A lower ratio proxies for credit scarcity and higher local financing costs $r^{L}$ in the model. We then sort Taobao vendors within each group a second time according to their credit scores into five credit score bins ranging from high credit risk in column 1 to low credit risk in column 5 . Table 1 , panel A, reports for each double sorted group the percentage of Taobao vendors using the online credit facility, i.e., the credit acceptance rate, and panel $\mathrm{B}$ reports their average (percentage) credit use of the total credit line.

For all five vendor groups sorted on the local Loan-to-GDP ratio, vendors with lower credit scores in the left-hand columns are more likely to use online credit (panel A) and on average use higher percentage out of credit line (panel B). For vendor locations in group $\mathrm{E}$ with the best local bank credit conditions, the acceptance rate of online credit increases from 16.60 percent for vendors in bin (5) with the highest credit scores to 33.77 percent for vendors in bin (1) with the lowest credit scores. In cities with a low loan-to-GDP ratio (group A), the percentage of firms using online credit increases even more steeply from 16.06 percent for vendors with high credit scores in bin (5) to 39.34 percent for firms with low credit scores in bin (1).

The acceptance rate of online credit varies by 5.57 and 0 percentage points when comparing locations of low and high loan-to-GDP ratios in bins (1) and (5), respectively. The vertical comparison in Table 1 suggests that FinTech credit compensates for city-level variation in the supply of traditional credit as predicted by
Proposition 3. Yet this variation in credit acceptance is much larger in the second dimension of sorting: The online credit acceptance rate increases by 17.17 to 22.74 percentage points when comparing firms with low and high credit scores in bins (1) and (5), respectively. In accordance with Proposition 2, vendors with low credit scores are much more likely to draw on the availability of online credit. We also note that Table 1 could have been constructed by conditioning on the city fixed effects depicted in Figure 2. Again, we obtain a very similar result with a steep increase in FinTech credit acceptance and FinTech credit use as vendors of higher credit risk are considered.

The evidence is also compatible with Proposition 1 whereby FinTech credit extends the frontier of credit availability to a large number of vendors with low credit scores that are potentially credit-constrained with respect to banking credit. But we can provide additional evidence that vendors with low credit scores often do not have bank access to credit. Using the GPS coordinates of each vendor we estimate the substitution effect between traditional bank credit and FinTech credit based on the distance of each Taobao vendor from the 10 or 20 closest bank branches. A larger physical bank distance generally makes online credit more attractive and increases the FinTech credit demand. But this substitution effect is strongest for Taobao vendors with high credit scores. Moving from the 25 percent high to the 25 percent low-quality borrower, we find that the FinTech credit demand sensitivity with respect to bank distance drastically decreases. This is not surprising if low-quality borrowers do not enjoy bank access in the first place: substitution effects between FinTech and traditional bank credit should largely vanish for low-quality borrowers without bank access.

Previous research on China's credit market gave conflicting assessments on the role of informal credit as a substitute for bank credit in explaining high private sector growth rates (Allen, Qian, and Qian 2005; Ayyagari, Demirgüç-Kunt, and Maksimovic 2010). The steep increase of FinTech credit use by borrower credit risk suggests that informal sources of credit are a very imperfect substitute for missing bank credit. The large take-up rates of FinTech credit suggest that informal credit is either not available or more expensive. 
Table 1-Online Credit Use by Local Credit-To-GDP Ratio and Credit Score

\begin{tabular}{|c|c|c|c|c|c|c|}
\hline & \multicolumn{5}{|c|}{ Vendor credit score rank } & \multirow[b]{2}{*}{$(1)-(5)$} \\
\hline & $\begin{array}{l}\text { Low } \\
(1)\end{array}$ & $(2)$ & (3) & $(4)$ & $\begin{array}{l}\text { High } \\
(5)\end{array}$ & \\
\hline \multicolumn{7}{|c|}{ Panel A. FinTech credit acceptance rate (in percent) } \\
\hline \multicolumn{7}{|c|}{ City-level bank credit-to-GDP } \\
\hline (A) Low & 39.34 & 31.86 & 26.68 & 21.95 & 16.60 & 22.74 \\
\hline (B) & 32.92 & 28.34 & 24.81 & 20.22 & 16.24 & 16.68 \\
\hline (C) & 39.03 & 31.99 & 26.78 & 21.69 & 16.61 & 22.42 \\
\hline (D) & 32.57 & 28.67 & 23.79 & 19.62 & 16.05 & 16.52 \\
\hline (E) High & 33.77 & 28.25 & 23.52 & 20.15 & 16.60 & 17.17 \\
\hline$(\mathrm{A})-(\mathrm{E})$ & 5.57 & 3.61 & 3.16 & 1.80 & 0 & \\
\hline \multicolumn{7}{|c|}{ Panel B. Average FinTech credit use (percent of credit line) } \\
\hline \multicolumn{7}{|c|}{ City-level bank credit-to-GDP } \\
\hline (A) Low & 21.05 & 19.91 & 16.96 & 13.86 & 10.47 & 10.58 \\
\hline (B) & 19.37 & 18.72 & 17.02 & 13.70 & 11.09 & 8.28 \\
\hline (C) & 21.48 & 21.39 & 17.95 & 14.93 & 11.17 & 10.31 \\
\hline (D) & 19.13 & 19.53 & 16.43 & 13.18 & 10.68 & 8.45 \\
\hline (E) High & 20.21 & 19.02 & 16.23 & 13.22 & 11.45 & 8.76 \\
\hline$(\mathrm{A})-(\mathrm{E})$ & 0.84 & 0.89 & 0.73 & 0.64 & -0.98 & \\
\hline
\end{tabular}

Notes: We report in panel A the percentage of Taobao vendors using online credit (credit acceptance rate) and in panel B the average credit use percentage. Vendors are sorted first by the local bank credit-to-GDP ratio into groups A to E. A second sort groups vendors into five bins according to the credit score of the vendor, ranging from low in column 1 to high in column 5.

\section{Conclusion}

FinTech credit providers like Ant Financial may enjoy a competitive advantage over traditional banks because of their cheaper distribution channels and due to their information advantage. The latter advantage should matter most for borrowers with low credit scores and implies that FinTech credit providers capture a larger market share in this market segment. FinTech firms can also be expected to expand the extensive market of credit to vendors previously excluded from bank credit. We confirm both predictions based on comprehensive data from one of China's largest FinTech credit providers.

Overall, FinTech credit contributes to a more inclusive financial system which creates credit access for borrowers excluded from traditional bank credit. The benefit of FinTech credit may therefore be largest in an emerging market country like China with underdeveloped credit markets. FinTech credit with its uniform national credit distribution has the additional benefit of integrating China's highly fragmented local credit markets for small firm (vendor) credit.
It also contributes to improved and fairer credit access for China's large rural population.

\section{REFERENCES}

Allen, Franklin, Jun Qian, and Meijun Qian. 2005. "Law, Finance, and Economic Growth in China." Journal of Financial Economics 77 (1): 57-116.

Ayyagari, Meghana, Asli Demirgüç-Kunt, and Vojislav Maksimovic. 2010. "Formal versus Informal Financial: Evidence from China." Review of Financial Studies 23 (8): 3048-97.

Hau, Harald, Yi Huang, Hongzhe Shan, and Zixia Sheng. 2018. "FinTech Credit, Financial Inclusion and Entrepreneurial Growth." Unpublished.

Livshits, Igor, James C. Mac Gee, and Michèle Tertilt. 2016. "The Democratization of Credit and the Rise in Consumer Bankruptcies." Review of Economic Studies 83 (4): 1673-1710.

Mann, Ronald J. 2006. Charging Ahead: The Growth and Regulation of Payment Card Markets. Cambridge: Cambridge University Press. 